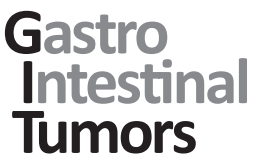

\title{
Cost Analysis of Biliary Drainage Using Metal versus Plastic Stents in Hepatocellular Carcinoma Patients with Obstructive Jaundice
}

\author{
Esam Elshimi $^{\mathrm{a}}$ Wesam Morad $^{\mathrm{b}}$ \\ ${ }^{a}$ Hepatology Department, National Liver Institute, Menoufia University, Shebin Al-Kom, \\ Egypt; ${ }^{\text {b}}$ Epidemiology and Preventive Medicine Department, National Liver Institute, \\ Menoufia University, Shebin Al-Kom, Egypt
}

\section{Keywords}

Hepatocellular carcinoma - Obstructive jaundice · Endoscopic retrograde cholangiopancreatography $\cdot$ Metal and plastic stents

\begin{abstract}
Background: The optimal method of biliary drainage for biliary obstruction caused by hepatocellular carcinoma (HCC) is controversial, and the possible endoscopic application of plastic and metal stents is the least invasive procedure to improve patients' quality of life. Aim: Our objective was to study cost evaluation based on a clinical efficacy of both procedures in a randomized trial comparing both approaches in patients with biliary obstruction caused by HCC. Methods: The strategy of management was based on clinical effectiveness of biliary drainage with either metal or plastic stents in 90 patients over a 1-year follow-up period. Total (direct and indirect) costs were evaluated. Results: The direct costs were EGP 40,857.84 and 21,802.62 per patient with plastic and metal stents, respectively. Concerning the indirect costs, EGP 888 and 454 were spent for each patient with plastic and metal stents, respectively. The differences in the costs resulted from patients with plastic stent insertion requiring more second endoscopic retrograde cholangiopancreatography procedures and more medication, medical consultation, and hospitalization during the year of follow-up. Conclusions: Based on this analysis, the use of metal stents rather than plastic stents in biliary drainage is more cost effective for this group of patients.




\section{Introduction}

In 1947, Mallory et al. [1] described the first case of obstructive jaundice caused by the invasion of cystic ducts by hepatocellular carcinoma (HCC) giving rise to biliary obstruction caused by thrombi from the tumor. Thereafter, many varying presentations have been reported. In 1975, Lin et al. [2] classified cases with biliary obstruction caused by HCC as "icteric type hepatoma," this type of HCC manifests with biliary obstruction in the early stage of HCC before the tumor becomes evident clinically or radiologically. HCC can lead to obstructive jaundice by many mechanisms, including growth of the mass until it fills the entire lumen of the ductal system partially or completely, growth of migrated fragments of separated tumor tissue to the lumen of the biliary system, and partial or complete intraluminal blood clots [3].

In such cases, the intra-ductal thrombus is the main reason for biliary obstruction, with an incidence of 1.2-9\% [4]. Mixed types of primary liver cancers (cholangiocarcinoma and HCC) have also been found and may represent a further added cause of obstructive jaundice. Infrequently, external compression on the bile ducts is applied by direct tumor encasement or by the enlarged lymphadenopathy at the porta hepatis [5].

Most primary lesions of icteric-type HCC patients are grossly infiltrative or mixed infiltrative and nodular. Usually, no tumor capsule formation can be found in the primary lesion [6]. The infiltrative presentation of this type of tumor may partly explain their early invasion of the portal veins and or biliary system regardless to the type or size of the tumor.

This type of HCC may be present even in the absence of a primary detectable mass [7]. Intraductal tumor is mostly attributed to invasion from the primary lesion and/or from an adjacent extensive malignant portal vein thrombus $[8,9]$.

Successful endoscopic retrograde cholangiopancreatography (ERCP) procedures date back to the 1960s. Since then, ERCP has come to be the therapeutic modality of choice for pancreaticobiliary diseases [10].

Biliary drainage by ERCP is the standard of care therapeutic modality for biliary drainage in patients with obstructive jaundice and cholangitis. Biliary decompression optimizes the clinical condition that in turn improves the patient's quality of life. Moreover, biliary drainage improves patient survival. Given that simple drainages increase survival between 2.5 and 4.5 months, adding palliative therapies to biliary drainage increases survival from 8 to 13.4 months [11]. Therefore, biliary drainage could improve the prognosis.

In clinical practice, ERCP and stent insertion in patients with HCC does not always seem to be the best therapeutic modality in the context of HCC and biliary obstruction. Some patients with biliary obstruction treated with ERCP and stenting showed incomplete relief of jaundice attributed to the background of liver cirrhosis. Brown and Covey [12] suggested that tumor ingrowth can invade inside the stent, leading to stent dysfunction.

The current modality of drainage is by stenting using metal or plastic stents [13-17]. Metal stents provide a lower stent dysfunction rate and offer prolonged patency over plastic stents. At the same time, patients with HCC and obstructive jaundice have a short survival time [11]. The cost effectiveness analysis between metal and plastic stents has been discussed in many clinical trials. However, the issue has not been studied in the context of HCC based on clinical efficacy and randomization comparing biliary drainage using metal versus plastic stents for obstructive jaundice in regards to cost analysis. 


\section{Patients and Methods}

Patients

In the current study, we evaluated 3,064 patients with obstructive jaundice between September 2015 and August 2018. Of these, 1,879 patients were eligible for ERCP, with 100 patients having biliary obstruction caused by HCC, from which 90 patients fulfilled our inclusion criteria. They were randomized for biliary drainage either by plastic or metal stents, thus forming 2 study groups: group I, 45 patients aged 44-73 years old, biliary drainage was achieved by metal stent insertion; group II, 45 patients aged 46-70 years old, biliary drainage was achieved by plastic stent insertion.

\section{Inclusion Criteria}

We included all patients with biliary obstruction caused by HCC who were eligible for ERCP according to National Liver Institute protocols. In the setting of obstructive jaundice and HCC, ERCP is the first choice to achieve biliary drainage with the exception of patients with recent band ligation for esophageal varices (within 2 weeks); upper gastrointestinal endoscopy is planned before ERCP if patients have a history of band ligation of between 2 and 4 weeks. All patients $\geq 18$ years with obstructive jaundice caused by HCC during the study period were included.

\section{Exclusion Criteria}

All patients unfit for anesthesia, with unsuitable coagulation profiles, previous stenting and dilatation during endoscopy, and HCC with other malignancies were excluded.

\section{Methods}

The analysis of costs was based on many studies comparing biliary drainage using metal stents versus plastic stents in the biliary drainage of patients with malignant biliary obstruction. In the current study, we compared the data on the utilized medical resources of all 90 included subjects in addition to the duration of time lost related to the stent occlusion and re-obstruction with its re-evaluation and management. We assessed the direct cost related to the consultation visits, ERCP procedure, imaging, laboratory investigation, hospitalizations, and medications used to treat complications. The indirect cost was calculated based on the time lost (in days) caused by disease burden multiplied by EGP 100 for each day (spent away from daily activity). In the current study, we randomized our patients to receive drainage with metal or plastic stents. The outcomes evaluated included the number of subsequent ERCP procedures and the duration in days away from daily life due to hospitalization. In the current trial, the strategy using metal stents decreased the need for secondary ERCPs and led to reduced complications. The current trial was conducted at the National Liver Institute University Hospital, a well-equipped government-based center for liver disease and endoscopy.

\section{General Considerations for Cost Determination}

We included the costs for all of the resources used in both groups of patients, as collected during the period of follow-up. Both the direct and indirect costs were tabulated (Table 1). We conducted this cost analysis assuming that all other factors remained the same outside disease- or procedure-related resources, especially because we only collected disease-related resource utilization, as described above. In other words, we assumed that there were no differences in transportation costs, in personal consumption of pharmaceutical drugs, or in utilization of medical care services other than for the related medical conditions in both groups. All procedures, physician fees, and duration of hospitalization, in addition to the complications related to the disease, were reported in the current trial. Included patients were asked to quantify their time spent away from their usual activity because of re-obstruction and the subsequent procedure or its complications. For each strategy (metal and plastic stenting), the average of total direct costs per patient was computed for each group, including the cost of the ERCP procedures (initial and subsequent), visits and investigations with physician fees (consultation costs were included in all procedures), and all costs of hospitalization.

\section{Follow-Up}

The studied patients were randomized to one of the studied groups. They were followed up for 1 year or until re-obstruction or death. Scheduled visits for follow-up were planned monthly. The pertinent periods of hospitalization were recorded, as defined by any hospital admission related to re-obstruction, or any adverse event related to the procedure. 


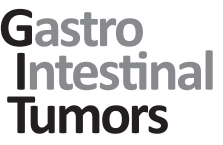

Table 1. Unit costs

\begin{tabular}{l|l}
\hline Gastrointest Tumors 2020;7:1-10 \\
\hline DOI: 10.1159/000503862 & $\begin{array}{l}\text { @ 2019 The Author(s). Published by S. Karger AG, Basel } \\
\text { www.karger.com/gat }\end{array}$ \\
\hline
\end{tabular}

Elshimi and Morad: Costs of ERCP in Obstructive Jaundice Caused by HCC

\begin{tabular}{lc}
\hline Cost item & Cost value, EGP \\
\hline $\begin{array}{l}\text { Visit (gastroenterology) } \\
\text { Consultation (gastroenterology) }\end{array}$ & 150 \\
Total cost for an ERCP procedure & 300 \\
$\quad$ with plastic stent application & 7,000 \\
Total cost for an ERCP procedure & \\
$\quad$ with metal stent application & 14,000 \\
Hospitalization for cholangitis & 4,224 \\
Average per diem cost for & \\
$\quad$ hospitalizations due to biliary re-obstruction & 350 \\
Cost of time lost per day & 75 \\
\hline
\end{tabular}

Values were rounded to the nearest integer in Egyptian pounds. ERCP, endoscopic retrograde cholangiopancreatography.

Sensitivity Analysis

Analysis of sensitivity was performed regarding the varying medical outcomes through the meaningful range of upper and lower quartiles of the units of the resources utilized multiplied by the costs per unit. Data were recorded and analyzed using SPSS 26 for Windows (SPSS Inc., Chicago, IL, USA). All tests of significance were two-tailed. $p$ values $<0.05$ were considered statistically significant. Comparison of variables representing continuous not normally distributed data was performed using the Mann-Whitney test.

\section{Results}

All cost results were calculated over the 1-year period parallel to the study duration and randomization. The values of cost expressed in this study are presented in Egyptian pounds (given the rapid changes of the value of the Egyptian pound versus the US dollar, we preferred the use of the Egyptian pound).

\section{Direct Costs}

Data regarding the used resources are reported in Table 2. Patients with plastic stents required more visits and the average cost attributable to these visits was more than in patients with metal stents. The plastic stent group required subsequent procedures more often and required more hospitalization days, visits, medications, and investigations than patients with metal stenting. Table 3 provides the averages of direct cost for each patient, including the upper and lower bounds based on the utilized medical resources reported in Table 2. ERCP and medications represented around two-thirds of all direct costs in patients with plastic stenting, and three-quarters in patients with metal stenting. For total direct costs, patients with plastic stents cost more money than patients with metal stents.

\section{Fees of Physicians}

The physician fees were calculated by direct estimation from the hospital management system.

\section{Costs of Hospitalization}

The costs of hospital admission were defined as the daily cost of hospital stay multiplied by number of days spent within the hospital derived from the hospital administration system. This resource included all overhead costs and institutional costs, excluding the fees of physi- 
Table 2. Medical resource utilization per patient

\begin{tabular}{lccc}
\hline & $\begin{array}{l}\text { Plastic stent group } \\
(n=45)\end{array}$ & $\begin{array}{l}\text { Metal stent group } \\
(n=45)\end{array}$ & $p$ value \\
\hline Total visits to gastroenterology & $6.56(1.0)$ & $2.77(0.4)$ & 0.0001 \\
Total visits to consultants & $7.2(2.1)$ & $3.1(0.81)$ & 0.0001 \\
Total ERCP procedures & $3.6(1.1)$ & $1.56(0.32)$ & 0.0001 \\
Total days of hospitalization & $5.7(1.8)$ & $1.65(0.25)$ & 0.0001 \\
Direct costs, EGP & & & 0.0001 \\
$\quad$ Visits to gastroenterology & $882.2(167.3)$ & $334.5(95.6)$ & 0.0001 \\
$\quad$ Visits to consultants & $1,000.1(241.6)$ & $487.3(75.9)$ & 0.0001 \\
$\quad$ All ERCP procedures & $3,378.2(823.4)$ & $14,189(634.2)$ & 0.0001 \\
$\quad$ Lab investigations & $1,701.4(401.5)$ & $1,320.4(137.6)$ & 0.0001 \\
$\quad$ Imaging & $5,810.2(1,080.7)$ & $2,360.3(732.6)$ & 0.0001 \\
$\quad$ Medications & $2,178.24(530.5)$ & $845.12(198.4)$ & 0.0001 \\
$\quad$ Follow-up & $4,027.5(1,165.7)$ & $1,612.8(623.8)$ & 0.0001 \\
$\quad$ Hospitalization & $1,198.3(287.3)$ & $600.1(87.4)$ & 0.0001 \\
$\quad$ Indirect costs, EGP & & & \\
$\quad$ Absence from work & & & \\
\hline
\end{tabular}

Data are presented as the mean (SD). Values were rounded to the nearest 2 decimals. The Student $t$ test was used to assess significant differences in the cost of plastic and metal stents. Differences in both formulas are because each patient differed in number of hospitalizations. Therefore, to calculate the cost of hospitalization per patient we added the number of each patient's hospitalizations then divided it by the total number of patients who were hospitalized, then multiplied by the mean cost of each hospitalization. ERCP, endoscopic retrograde cholangiopancreatography.

Table 3. Total direct and indirect costs

\begin{tabular}{|c|c|c|c|c|c|c|c|c|c|}
\hline & & \multicolumn{4}{|c|}{ Patients with plastic stents } & \multicolumn{4}{|c|}{ Patients with metal stents } \\
\hline & & $\begin{array}{l}\text { average cost } \\
\text { per patient, } \\
\text { EGP }\end{array}$ & $\begin{array}{l}\text { proportion of } \\
\text { total direct/ } \\
\text { indirect costs, \% }\end{array}$ & $\begin{array}{l}\text { lower } \\
\text { bound, } \\
\text { EGP }\end{array}$ & $\begin{array}{l}\text { upper } \\
\text { bound, } \\
\text { EGP }\end{array}$ & $\begin{array}{l}\text { average cost } \\
\text { per patient, } \\
\text { EGP }\end{array}$ & $\begin{array}{l}\text { proportion of } \\
\text { total direct/ } \\
\text { indirect costs, } \%\end{array}$ & $\begin{array}{l}\text { lower } \\
\text { bound, } \\
\text { EGP }\end{array}$ & $\begin{array}{l}\text { upper } \\
\text { bound, } \\
\text { EGP }\end{array}$ \\
\hline \multirow{9}{*}{$\begin{array}{l}\text { Direct } \\
\text { costs }\end{array}$} & Gastroenterology visits & 882.2 & 2.16 & 240 & 880 & 334.5 & 1.53 & 110 & 330 \\
\hline & Consultant visits & $1,000.1$ & 2.45 & 300 & 875 & 487.3 & 2.24 & 135 & 450 \\
\hline & Investigations & $3,378.2$ & 8.27 & 1,000 & 3,000 & $1,320.4$ & 6.06 & 450 & 1,200 \\
\hline & Imaging & $1,701.4$ & 4.16 & 520 & 1,550 & 653.2 & 2.99 & 220 & 600 \\
\hline & ERCP procedure & 21,880 & 53.55 & 7,500 & 21,000 & 14,189 & 65.08 & 4,750 & 14,000 \\
\hline & Medications & $5,810.2$ & 14.22 & 1,900 & 5,750 & $2,360.3$ & 10.83 & 780 & 2,240 \\
\hline & Hospitalizations & $4,027.5$ & 9.86 & 1,230 & 3,890 & $1,612.8$ & 7.39 & 575 & 1,580 \\
\hline & Follow-up & $2,178.24$ & 5.33 & 720 & 2,100 & 845.12 & 3.88 & 284 & 788 \\
\hline & Total direct costs & $40,857.84$ & 100 & 13,410 & 39,045 & $21,802.62$ & 100 & 7,304 & 21,188 \\
\hline \multirow{5}{*}{$\begin{array}{l}\text { Indirect } \\
\text { costs }\end{array}$} & Time spent on gastroenterology visits & 260 & 29 & 120 & 350 & 95 & 21 & 50 & 150 \\
\hline & Time spent on ERCP procedures & 284 & 32 & 130 & 330 & 140 & 31 & 60 & 230 \\
\hline & Time spent at hospital & 124 & 14 & 50 & 180 & 61 & 13 & 30 & 100 \\
\hline & Time spent away from ADL & 220 & 25 & 130 & 300 & 158 & 35 & 90 & 250 \\
\hline & Total indirect costs & 888 & 100 & 430 & 1,160 & 454 & 100 & 230 & 730 \\
\hline \multicolumn{2}{|c|}{ Total direct and indirect costs, EGP } & $41,745.84$ & & 13,840 & 40,205 & $22,256.62$ & & 7,534 & 21,918 \\
\hline
\end{tabular}

Values were rounded to the nearest integer. Low and high values are based on the lower (25\%) and upper (75\%) quartiles. ADL, activities of daily living; ERCP, endoscopic retrograde cholangiopancreatography.

cians, multiplied by the total average costs per weighted case to express the final costs of hospital admission for each patient. We recorded the per diem costs caused by hospital admissions attributable to complication-related hospital admissions for the studied patients. The per diem costs were the average costs of an adult hospitalization registered for one of the commonly obstructive jaundice-related adverse events and their impacts on costs and hospitalizations. 
Table 4. Time lost in days per patient

\begin{tabular}{lllr}
\hline & $\begin{array}{l}\text { Plastic stent group } \\
(n=45)\end{array}$ & $\begin{array}{l}\text { Metal stent group } \\
(n=45)\end{array}$ & $p$ value \\
\hline Total time spent for visits in gastroenterology & $28.78(8.72)$ & $13.82(4.6)$ & 0.0001 \\
Total time spent to undergo ERCP & $12.29(4.1)$ & $3.08(1.0)$ & 0.0001 \\
Total time spent at hospital & $42.89(9.72)$ & $13.23(4.8)$ & 0.0001 \\
Total of additional time spent away from ADL ${ }^{1}$ & $16.37(5.3)$ & $5.42(1.6)$ & 0.0001 \\
\hline
\end{tabular}

Data are presented as the mean number of days (SD). Values were rounded to the nearest 2 decimals. The Mann-Whitney test was used to assess significant differences in the cost of plastic and metal stents. ADL, activities of daily living; ERCP, endoscopic retrograde cholangiopancreatography.

${ }^{1}$ Differences in the sum of all the days spent away from ADL for all patients/number of patients in both formulas arise because patients had variable numbers of events causing days away from ADL.

\section{Costs of Procedures}

We estimated the direct cost for therapeutic ERCP, depending on whether plastic or metal stents were inserted for biliary drainage in the study populations. Additional ERCP procedures were included in the patient's management plan if they developed biliary re-obstruction. In each comparison group, the percentages of procedure repetition as a result of re-obstruction in both groups were 3.6 times in patients with plastic stenting and 1.56 times in patients with metal stenting.

\section{Indirect Costs}

Table 4 presents the estimated time lost by each patient relevant to the disease burden (in days). In terms of time lost, all categories of indirect cost (procedures, hospitalizations, and visits, in addition to the time spent away from daily activity), significantly contributed to the total indirect cost burdens. Table 4 shows that patients with plastic stenting required more time away from their daily activity. The total costs are presented in Table 3, demonstrating that the biggest difference came from indirect costs relating to time allocated for procedures followed by time spent away from daily activity in the plastic stenting group, while in patients with metal stenting the time spent away from daily activity was more than the time needed for procedures.

Figure 1 expresses the absolute per patient cost values. On average, the cost for management of a patient with obstructive jaundice in patients with HCC using plastic stents was EGP 41,745.84 versus 22,256.62 when adopting biliary drainage using metal stents (for each patient). In other words, ERCP with biliary drainage using metal stents rather than plastic stents would save on average EGP 19,489.22 per patient.

\section{Indirect Cost Evaluation}

Based on a human capital approach $[18,19]$, the indirect costs were evaluated on the basis of the loss of productivity, based on times lost caused by stent occlusion and or cholangitis. This time is defined as any time lost that resulted in a patient's absence from daily life, and represented the sum of the time, in days, required for procedures, hospital admission, follow-up procedures, and the time needed for medical consultations. The time away from daily activity was reported from patients' questionnaires unless specified as above. The value of a patient's time were evaluated on the basis of the hourly national Egyptian income. For the time consumed away from usual activity, specific hourly values were applied according to the patient's sex and age. For length of hospitalization in addition to the times spent for 


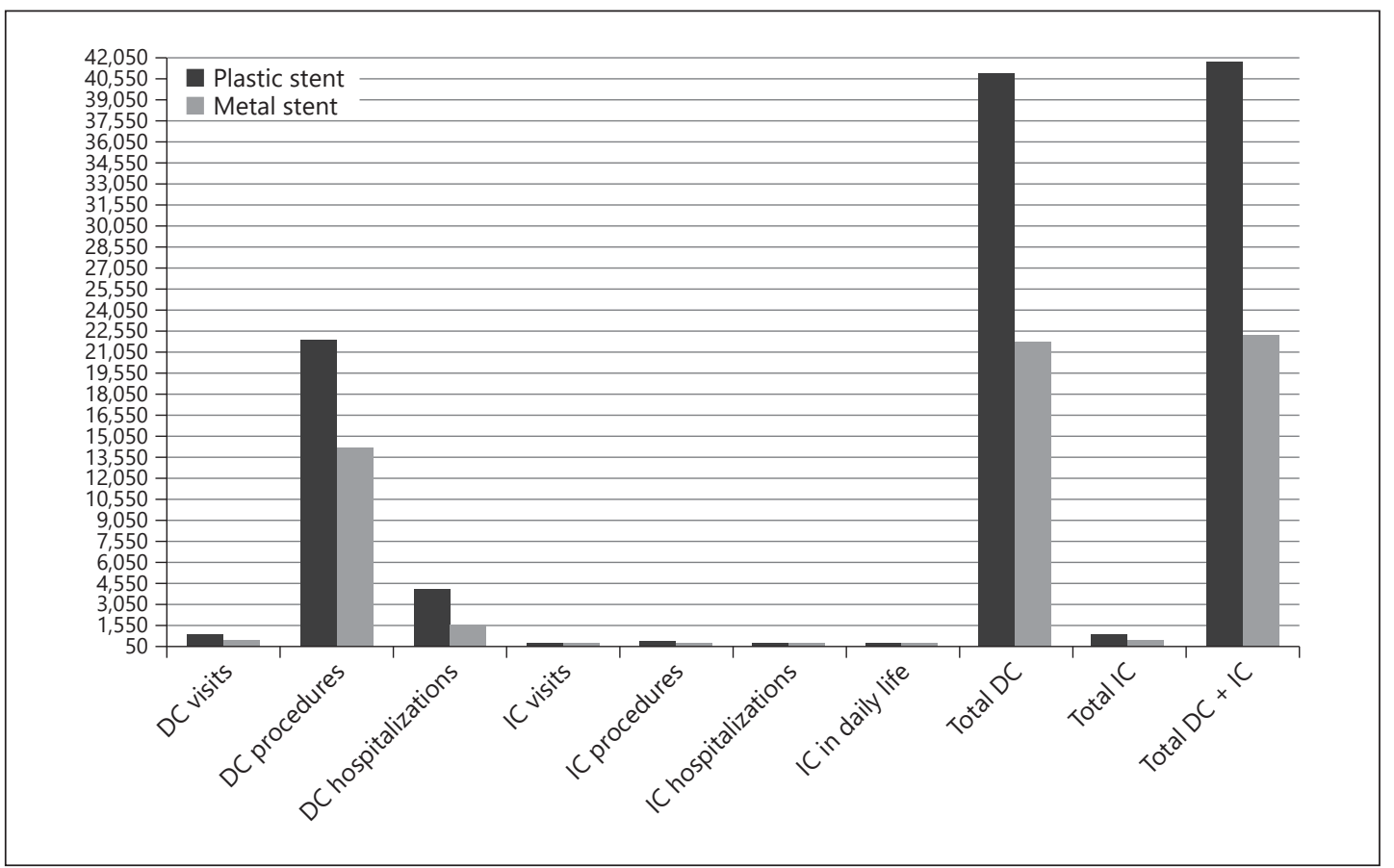

Fig. 1. Per patient costs over 12 months. ERCP, endoscopic retrograde cholangiopancreatography; DC, direct costs; IC, indirect costs.

ERCP, a unified average hourly wage was used for all studied patients. We supposed that each patient spent half a day for consultation visits, imaging, and laboratory investigation, and 1 day to undergo an ERCP procedure. The unit costs are reported in Table 1.

\section{Discussion}

Based on the fact that a metal stent has a longer patency time than a plastic stent in patients with pancreatic cancer, periampullary tumors, and cholangiocarcinoma, metal stents are the preferred drainage modality for patients with non-operable and un-resectable malignant biliary obstruction [13]. However, this is not the same for patients with HCC because of the hypervascular nature of the tumor and the underlying mechanisms of biliary obstruction in patients with HCC. Furthermore, HCC has a different tumor biology, coagulopathies, and usually occurs on background cirrhosis where the survival time is shorter [3].

This study compared the cost of ERCP and metal stenting versus ERCP and plastic stenting for the palliation of biliary obstruction caused by inoperable HCCs. With metal stents, tumor in-growth through the metal mesh of the stent remains the major cause of stent occlusion and dysfunction in uncovered stents. In fully covered metal stents, tumor overgrowth and stent migration are the main causes of cholangitis and stent dysfunction. Sludge, bacterial infection, and biofilm formation represent the main causes of occlusion in plastic stents [13]. Therefore, drainages with wider caliber stents have been suggested to function better, and this seems to be the most important factor affecting a stent's life, causing the difference between plastic and metal stents.

Moreover, in HCC stent dysfunctions caused by clogging bacterial colonization are associated with liver failure and worsening of the liver condition and toxemia. Subsequent ERCP 
procedures are prevented after failure of drainage or stent dysfunction. However, debate exists regarding which type of stents may be the best draining modality. These uncertainties come from the fact that metal stents offer better patency and fewer subsequent ERCP procedures with their concomitant risks and costs.

In our study, we have quantified the direct cost of all used utilized resources, and also captured the indirect cost caused by time lost by the patients because of their medical conditions and the time lost for diagnosis and treatments. However, we were not able to estimate the fees of transportation and the time-related costs of patients' caregivers. The total costs were EGP 41,745.84 per patient in the plastic stent group and EGP 22,256.62 per patient in the metal stent group, representing a difference of EGP 19,489.24.

ERCP procedures with metal stent application are more expensive than using plastic stents because of the added cost of a metal stent. However, stent dysfunction and/or re-obstruction accrues the expenses of another procedure, further hospitalization, and fees of medical consultations and investigations. Moreover, the patient requires more time away from their daily activities. Thus, there are greater costs resulting from increased numbers of ERCP procedures and higher frequency of hospital admissions among patients with plastic stents. Consequently, direct costs represented the biggest difference between both strategies over a 1-year period.

These findings were not surprising because ERCP with plastic stent application is known to incur more procedures, bearing significantly greater costs. This finding is simply explained by the number of patients who developed stent dysfunction and underwent further ERCP based on their clinical conditions as well as the subsequent hospitalizations noted in patients in the plastic stent group.

In our study, many clinical and methodological issues are worth highlighting. The findings, particularly the information relevant to the clinical efficacy of both strategies and probabilities, are drawn directly from our center. Therefore, our data are not theoretical suggestions and represent the true findings of our clinical observations. Moreover, the clinical relevancies are obviously heightened; indeed, we have reported all used medical resources through the prospective gathering of patients' self-reported questionnaires and actual data in the hospital medical management system. Although our data were more generalizable because the current study was designed to rate cost effectiveness, the findings may still be limited by lack of external validation, especially as we carried out the current study at our center, where the selection of patients was more systematized and organized than in settings in general practice, and also the professionalism of our center in dealing with patients with liver disease as a wellequipped government-based tertiary referral center should be taken into account. However, our trial, to the best our knowledge, is the first such report in the literature to measure the direct clinical impacts of ERCP with plastic and metal stents in the setting of biliary obstruction caused by HCCs.

Another limitation of our study came from the absence of standardization of physician fees in Egypt. However, these fees represented just a small part of the direct costs. We also recorded all required follow-up findings reported by assistant nurses, although 6 diagnoses were identified for the per diem calculation in the current cost analyses (cardiopulmonary, cholangitis, pancreatitis, bleeding, and perforation). Cholangitis and stent dysfunction represented the most commonly encountered complications related to ERCP procedures and remain the major causes of re-endoscopy.

In the medical field, indirect costs are defined as the loss of patient productivity based on the concept of opportunity cost $[18,20]$. The cost was computed according to capital approaches in individuals, and is usually applied in the field of medical economics and expressed as an indirect cost and recommended when adopting societal perspectives. Based on the impossible equities in the labor market and other conceptual requirements, even this 
method may lead to overestimates and adopts general assumptions [18, 21-23]. However, the methods of making these estimates remain a matter of controversy $[20,21,23,24]$, with some authors advocating the frictional cost method instead [25, 26]. Unfortunately, this alternative method needs an extensive amount of detailed information, making it seldom applicable [21].

The indirect cost was calculated from the general average wage rate for age and gender for times away from daily activity due to disease burden, either the time spent at the hospital or the post-procedure time spent for follow-up. Hence, it was difficult to estimate the real individual earnings of each studied patient $[18,21,22]$. The calculation of time lost was based on the reported length of hospital admissions, plus the time spent away from daily activities. In addition, we standardized the assumed times of half a day for the investigations and follow-up visits and 1 day for the ERCP procedure. However, the recorded times spent away from daily activity could be affected by the limitation of recall bias. A more accurate approach could be to consider the daily patients' notes regarding time lost away from activities [27] and the necessary transportation times; however, this appears inapplicable in the routine clinical practice.

In this context, we did not calculate the cost of time attributable to caregivers, as it was difficult to estimate in the current study as well as in other studies discussing similar issues. Moreover, the quality of life was not assessed between both groups. Despite the limitations of the current study, to the best of our knowledge it is the first in the literature to address a cost analysis in this context.

\section{Conclusions}

The present findings in the current cost analysis were based on a randomized study and compared ERCP strategies with plastic and metal stents, suggested significant differences in the total per patient cost between the groups. The increment of EGP 19,489.24 for each patient favors the metal stent strategy, principally due to the reduced hospitalization and procedural costs; however, larger trials are warranted to study the impact of indirect cost measurements. These data mirror the cost effectiveness findings regarding the cost of ERCP procedures using plastic stents compared with metal stents given the longer patency of metal stents over plastic stents, which decreases the need for subsequent procedures. These findings also emphasize the further advantage of ERCP with metal stents in decreasing the number of cases at a center with a high ERCP volume.

\section{Statement of Ethics}

All participants gave their written informed consent relevant to the current study. Ethical approval was obtained in November 2016 from the National Liver Institute ethical committee board (IRB No. IRB00003413) and according to the ethical guidelines of the 1975 Declaration of Helsinki.

\section{Disclosure Statement}

The authors have no conflicts of interest to disclose.

\section{Funding Sources}

There was no financial support relating to this work. 


\section{Author Contributions}

Conception and design: E.E. Acquisition of data: E.E., W.M. Analysis and interpretation of data: W.M. Drafting the article: W.M., E.E. Revision for intellectual content: E.E., W.M. Final approval of the completed article: E.E.

\section{References}

1 Mallory TB, Castleman B, Parris EE. Case records of the Massachusetts General Hospital. N Engl J Med. 1947; 237:673-6.

2 Lin TY, Chen KM, Chen YR, Lin WS, Wang TH, Sung JL. Icteric type hepatoma. Med Chir Dig. 1975;4(5-6):26770.

3 Qin LX, Tang ZY. Hepatocellular carcinoma with obstructive jaundice: diagnosis, treatment and prognosis. World J Gastroenterol. 2003 Mar;9(3):385-91.

4 Ikenaga N, Chijiiwa K, Otani K, Ohuchida J, Uchiyama S, Kondo K. Clinicopathologic characteristics of hepatocellular carcinoma with bile duct invasion. J Gastrointest Surg. 2009 Mar;13(3):492-7.

5 Peng SY, Wang JW, Liu YB, Cai XJ, Deng GL, Xu B, et al. Surgical intervention for obstructive jaundice due to biliary tumor thrombus in hepatocellular carcinoma. World J Surg. 2004 Jan;28(1):43-6.

6 Orimo T, Kamiyama T, Yokoo H, Wakayama K, Shimada S, Tsuruga Y, et al. Hepatectomy for hepatocellular carcinoma with bile duct tumor thrombus, including cases with obstructive jaundice. Ann Surg Oncol. 2016 Aug;23(8):2627-34.

7 Chen MF. Icteric type hepatocellular carcinoma: clinical features, diagnosis and treatment. Chang Gung Med J. 2002 Aug;25(8):496-501.

8 Buckmaster MJ, Schwartz RW, Carnahan GE, Strodel WE. Hepatocellular carcinoma embolus to the common hepatic duct with no detectable primary hepatic tumor. Am Surg. 1994 Sep;60(9):699-702.

$9 \mathrm{Hu}$ J, Pi Z, Yu MY, Li Y, Xiong S. Obstructive jaundice caused by tumor emboli from hepatocellular carcinoma. Am Surg. 1999 May;65(5):406-10.

10 McCune WS, Shorb PE, Moscovitz H. Endoscopic cannulation of the ampulla of Vater: a preliminary report. Gastrointest Endosc. 1968;34(3):278-80.

11 Lai EC, Lau WY. Hepatocellular carcinoma presenting with obstructive jaundice. ANZJ Surg. 2006 Jul;76(7):631-6.

12 Brown KT, Covey AM. Management of malignant biliary obstruction. Tech Vasc Interv Radiol. 2008 Mar;11(1): 43-50.

13 Park S, Park JY, Chung MJ, Chung JB, Park SW, Han KH, et al. The efficacy of endoscopic palliation of obstructive jaundice in hepatocellular carcinoma. Yonsei Med J. 2014 Sep;55(5):1267-72.

14 Bonnel D, André T, Mader B, Lefebvre JF, Bensoussan E, Liguory C. Malignant biliary obstruction, general review and clinical practice. Bull Cancer. 2013 May;100(5):443-52. French. https://doi.org/10.1684/bdc.2013.1736.

15 Soderlund C, Linder S. Covered metal versus plastic stents for malignant common bile duct stenosis: a prospective, randomized, controlled trial. Gastrointest Endosc. 2006 Jun;63(7):986-95.

16 Yoon WJ, Ryu JK, Yang KY, Paik WH, Lee JK, Woo SM, et al. A comparison of metal and plastic stents for the relief of jaundice in unresectable malignant biliary obstruction in Korea: an emphasis on cost-effectiveness in a country with a low ERCP cost. Gastrointest Endosc. 2009 Aug;70(2):284-9.

17 Levy MJ, Baron TH, Gostout CJ, Petersen BT, Farnell MB. Palliation of malignant extrahepatic biliary obstruction with plastic versus expandable metal stents: an evidence-based approach. Clin Gastroenterol Hepatol. 2004 Apr;2(4):273-85.

18 Drummond MF. Methods for the economic evaluation of health care programmes. 3rd ed. Oxford: Oxford University Press; 2005.

19 Culyer AJ, Newhouse JP, Pauly MV, et al. Handbook of health economics. Amsterdam: Elsevier; 2000.

20 Haddix AC, Teutsch SM, Corso PS. Prevention effectiveness: a guide to decision analysis and economic evaluation. 2nd ed. New York: Oxford University Press; 2002.

21 Zhang W, Bansback N, Anis AH. Measuring and valuing productivity loss due to poor health: a critical review. Soc Sci Med. 2011 Jan; 72(2):185-92.

22 CADTH Methods and Guidelines. Guidelines for the economic evaluation of health technologies. Ottawa: Canadian Agency for Drug and Technologies in Health; 2006.

23 Pritchard C, Sculpher M. Productivity costs: principles and practice in economic evaluation. London: Office of Health Economics; 2000.

24 Krol M. Productivity costs in economic evaluations. Rotterdam: Optima Grafische Communicatie; 2012.

25 Goeree R, O'Brien BJ, Blackhouse G, Agro K, Goering P. The valuation of productivity costs due to premature mortality: a comparison of the human-capital and friction-cost methods for schizophrenia. Can J Psychiatry. 1999 Jun;44(5):455-63.

26 Koopmanschap MA, Rutten FF, van Ineveld BM, van Roijen L. The friction cost method for measuring indirect costs of disease. J Health Econ. 1995 Jun;14(2):171-89.

27 Groover M. Work Systems and Methods, Measurement, and Management of Work. Pearson. International Edition. Upper Saddle River (NJ): Pearson; 2007. 